\title{
New Editorial Board members from China
}

\author{
Steffen Pauly
}

Published online: 2 December 2011

(C) Springer-Verlag 2011

Since the foundation of Analytical and Bioanalytical Chemistry (ABC) 10 years ago, China has developed and changed dramatically. Research, including analytical and bioanalytical science, has been an integral part of this change. The development of research has been reflected in $\mathrm{ABC}$ : from its very beginning, the journal has always had a representative from China on its International Advisory Board. Since 2006, the Chinese Society of Chromatography has been one of our supporting societies. Today, not only a significant share of $A B C$ publications originate from China, but also much of the online usage of the journal is from China. Consequently, the number of Chinese Advisory Board members has grown over the years.

It is with great pleasure that I can now announce two further reputed scientists who have joined the Editorial Board, bringing the total to six. To reflect the importance of China today, Prof. Lihua Zhang has been appointed as Regional Editor China starting in January 2012. In this function, she will both be an ambassador for the journal in China and an expert advisor for the ABC Editors.
Furthermore, Prof. Qiuquan Wang has become a member of the $\mathrm{ABC}$ International Advisory Board.

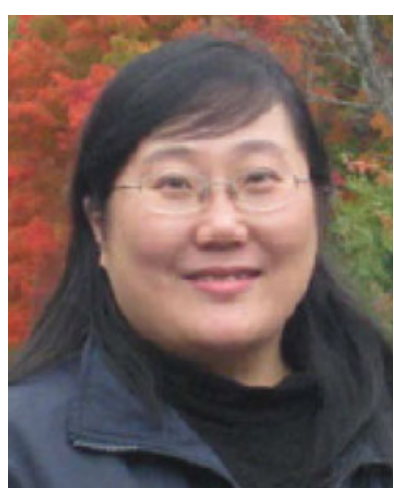

\section{Lihua Zhang}

is a Professor at Dalian Institute of Chemical Physics, Chinese Academy of Sciences. Her research and interests focus on the development of new separation and identification methods for both qualitative and quantitative analysis of proteomes, by developing novel sample preparation techniques, multidimensional liquid-phase-based platforms, and coupling with mass spectrometry. She received her $\mathrm{PhD}$ degree from Dalian Institute of Chemical Physics, Chinese Academy of Sciences, in 2000 after cooperative research with the National Research Center for Health and Environment (Germany), followed by a postdoctoral position at the

S. Pauly $(\bowtie)$

Analytical and Bioanalytical Chemistry, Springer,

Tiergartenstrasse 17,

69121 Heidelberg, Germany

e-mail: abc@springer.com 
University of Tokushima (Japan). She obtained her present position in 2003. Professor Zhang has authored more than 70 journal and conference articles, applied for five domestic and international patents, and contributed to six Chinese and English books.

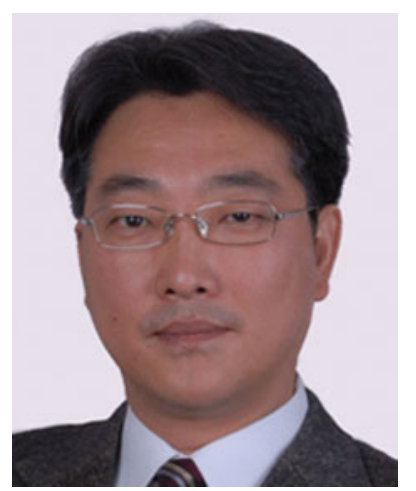

\section{Qiuquan Wang}

is a Professor at and Director of the Institute of Analytical Science, College of Chemistry \& Chemical Engineering, Xiamen University. His research interests include environmental and bioanalytical chemistry, metallomics, and quantitative proteomics. In particular, he develops novel interfaces for coupled systems, combining chromatographic/electrophoretic separation and atomic/mass-spectrometric detection. These techniques are used for the analysis of key environmental and biological elements as well as for determination and speciation of organic pollutants to study accumulation and phytoremediation. He received his $\mathrm{PhD}$ degree in 1998 from Gunma University (Japan) and became Associate Professor of Analytical Chemistry at the Department of Chemistry, Xiamen University, obtaining his present position in 2004. He has published more than 50 articles.

While cherishing the European roots of $\mathrm{ABC}$, we will continue to foster the broad, international appeal of the journal and look forward to a successful collaboration with our board members from China and equally all other countries and regions in this endeavor. Likewise, we appreciate the continued support from authors and reviewers all over the world, which has essentially made $\mathrm{ABC}$ what it is today.

On behalf of the Editors

Steffen Pauly 